\section{Point of Sale Displays Influence Consumer Decisions to Purchase Native Grasses}

\author{
Diane M. Narem, Mary Hockenberry Meyer ${ }^{2}$, Chengyan Yue ${ }^{1}$, \\ and Nicole Roth
}

ADDITIONAL INDEX WORDs. Lepidoptera, pollinators, sustainable landscapes, advertising, consumer knowledge, marketing

Summary. The demand for native plants has been increasing as consumers exhibit stronger interest in sustainable gardening and landscaping. To determine whether point of sale (POS) displays increased consumer knowledge of native grass (Poaceae) benefits and affected consumer purchases, a marketing study was conducted over 2 years at five garden centers in Minnesota. A POS display poster and plant tags listing four benefits of native grasses were displayed at the garden centers in 2016 and 2017. We surveyed 341 consumers at these garden centers to understand consumer knowledge of native grasses and the influence of the POS display. Respondents totaled $84(30.7 \%)$ who indicated they had bought a native grass that day, and of those $84,54(64.3 \%)$ had seen the display. The binary probit model estimates showed that seeing the POS display increased the likelihood of a native grass purchase. If a consumer had previously purchased a native grass, they were more likely to purchase a native grass again. Consumers who expressed a greater willingness to purchase native grasses based on their environmental benefits were more likely to purchase a native grass. However, neither the level of knowledge that consumers possessed about native grasses nor demographics significantly increased likelihood of purchase.

$\mathrm{T}$ The demand for native plants has been increasing as consumers exhibit stronger interest in sustainable gardening and landscaping (Brzuszek et al., 2010; Hamill, 2005; Helfand et al., 2006; Kiesling and Manning, 2010; Yue et al., 2015). A native species is defined by the U.S. Fish and Wildlife Service as "with respect to a particular ecosystem, a species that, other than as a result of an introduction, historically occurred, or currently occurs in that ecosystem" (U.S. Fish and Wildlife Service, 2001). Many native plants are drought tolerant (O'Brien, 1996), able to thrive in tough conditions (Brzuszek and Harkess, 2009), and provide critical habitat and food for wildlife, including birds and herbivorous insects (Tallamy and Shropshire, 2009). All these characteristics make native plants

Department of Horticultural Science, University of Minnesota, 1970 Folwell Avenue, St. Paul, MN 55108

We thank our funding source, the U.S. Department of Agriculture's National Institute of Food and Agriculture, and the Minnesota Department of Agriculture Specialty Crop Block Grant program. We also acknowledge our internal reviewers Emily Hoover and Michael Heger.

${ }^{1}$ Author is affiliated with both the Department of Horticultural Science and Department of Applied Economics

${ }^{2}$ Corresponding author. E-mail: meyer023@umn.edu. https://doi.org/10.21273/HORTTECH04124-18 desirable for ecologically conscious gardeners and landscape designers.

Native grasses provide many of these environmental benefits. They are low-maintenance plants that need little fertilizer or water once established and can grow in tough conditions and unique sites (Meyer, 2013). Grasses provide habitat for grassland birds and are a critical food and shelter source for numerous species of butterfly and moth (Lepidoptera) larvae (Narem and Meyer, 2017a). Narem and Meyer (2017a) compiled documented associations of 17 dominant native prairie grasses and 37 native butterflies and moths in Minnesota alone. Although not as efficient as bees (Anthophila), butterflies and moths are incidental pollinators that can be important for certain plant species (Hahn and Brühl, 2016; Jennersten, 1984). Even though numerous species of butterflies and moths share this relationship with native grasses, it is not well known to horticulturists, gardeners, or consumers.
Research has shown the public values policy such as water and energy savings (Yue et al., 2015) along with efforts that protect pollinators, such as bees, but also including butterflies, which are incidental pollinators (Breeze et al., 2015; Diffendorfer et al., 2014). Consumers are very interested in plants produced locally (Yue et al., 2011) and are willing to pay a premium for locally grown plants $[\$ 0.22$ (Khachatryan et al., 2014)]. Citizens surveyed in the United Kingdom were willing to pay $£ 13.4$ (\$18.59) in annual taxes per individual to support pollinator conservation (Breeze et al., 2015). U.S. households were willing to spend an estimated total of $\$ 4.78$ to $\$ 6.64$ billion on monarch (Danaus plexippus) conservation-related activities (Diffendorfer et al., 2014).

Valuation of pollinators has influenced consumer preference and purchasing decisions at the retail level (Khachatryan et al., 2017; Wollaeger et al., 2015). Khachatryan et al. (2017) found that, hypothetically, consumers were willing to pay $\$ 1.81$ to $\$ 1.84$ more for plants labeled as "pollinator friendly." However, how consumers express their valuation of pollinators depends on their awareness and knowledge about pollinator issues as well as the content of advertising materials (Rihn and Khachatryan, 2016; Wollaeger et al., 2015). Wollaeger et al. (2015) found that consumers would pay $\$ 0.96$ to $\$ 2.10$ more for plants labeled "bee-friendly" than for plants labeled "grown with traditional pest management practices." Rihn and Khachatryan (2016) found that on average consumers preferred "pollinatorfriendly" plant labels, but those who were aware of neonicotinoid pesticides, a contentious pollinator issue, showed a stronger preference for "neonic-free" plant labels and a greater purchase likelihood for "neonic-free" plants than consumers who were not aware of neonicotinoid pesticides. This indicates that consumer education can be an important tool to influence consumer preference and buying decisions. In a study by Brzuszek and Harkess (2009), native plant retailers

\begin{tabular}{llll}
\hline $\begin{array}{l}\text { Units } \\
\begin{array}{l}\text { To convert U.S. to SI, } \\
\text { multiply by }\end{array}\end{array}$ & U.S. unit & SI unit & $\begin{array}{l}\text { To convert SI to U.S., } \\
\text { multiply by }\end{array}$ \\
\hline 0.4047 & acre $(\mathrm{s})$ & ha & 2.4711 \\
2.54 & inch(es) & cm & 0.3937
\end{tabular}


indicated the best way to increase native plant sales was through consumer education using specific campaigns and POS displays. Hall and Dickson (2011) suggested incorporating marketing messages that highlight plants environmental benefits to "maintain the industry's sense of value and relevance" and also appeal to consumers.

POS displays are promotions located in the retail space to draw attention to specific products or special events and can include shelf edging, display stands, posters, banners, and plant tags (Barton and Behe, 2017). The 2014 National Green Industry Survey found almost all green industry retail organizations use POS displays (Barton and Behe, 2017). Marketing research has shown that POS displays increase sales of the product they are promoting (Huddleston et al., 2015; McKinnon et al., 1981). However, other variables can influence the effectiveness of a POS display, such as the product price, in-store sales, or the set-up of the store (Areni et al., 1999).

The objective of this study was to determine whether an informational POS display increased consumer knowledge of native grasses and whether it influenced consumer purchasing decisions, resulting in increased sales. Native plants are popular in Minnesota, and the Minnesota Department of Agriculture uses U.S. Department of Agriculture, National Institute of Food and Agriculture research funding to promote marketing and sales of native plants. We hypothesized that if consumers knew the benefits of grasses native to Minnesota and how these plants support butterflies, moths, and other wildlife, they would be more willing to purchase these grasses, thus increasing sales.

\section{Materials and methods}

POS MATERIALs. We selected messages that succinctly conveyed the benefits of grasses, were easy to understand, and would be valued by consumers. The messages were as follows: attracts wildlife, feeds butterflies and moths, reduces soil erosion, and no pesticides or fertilizer needed. POS display materials with these messages were distributed to four garden centers in 2016 and an additional garden center (total of five) in 2017. Three of the garden centers specialized
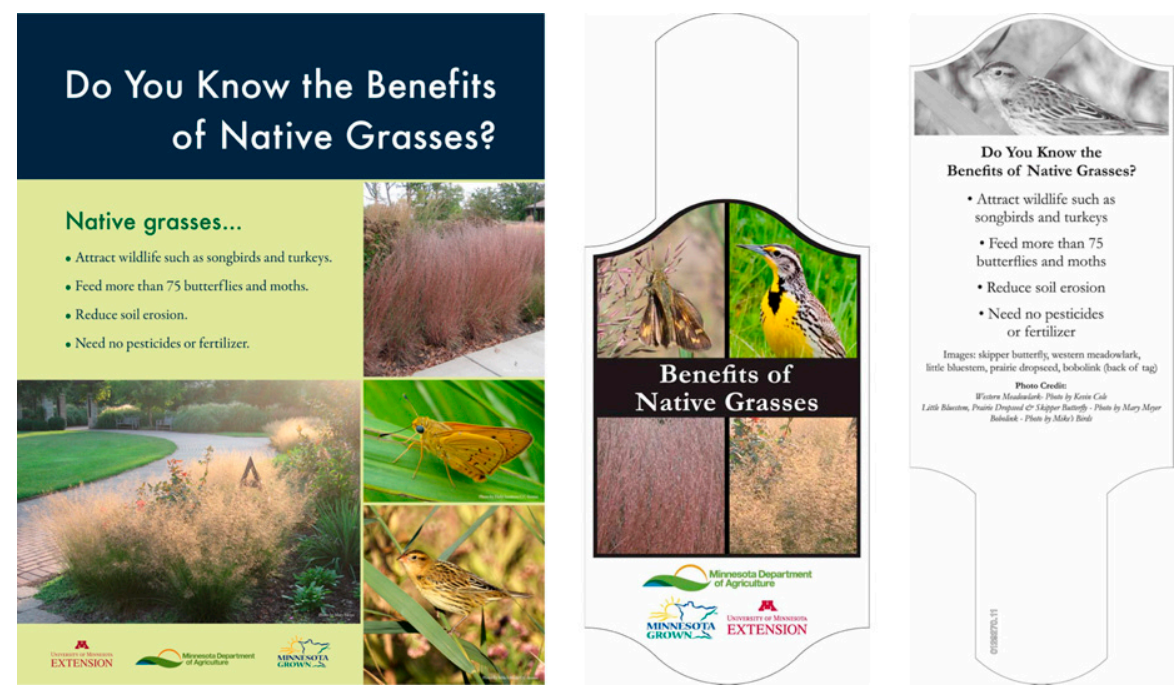

Fig. 1. Point of sale display poster and plant tags used in native grass marketing study at Minnesota garden centers in 2016-17. The poster was printed on $22 \times 28$ inches Dibond material (3A Composites USA, Inc., Davidson, NC). The tags were printed in two sizes: $2 \times 4.68$ inches and $3 \times 7.65$ inches; 1 inch $=2.54 \mathrm{~cm}$.

in native plants. The remaining two garden centers (including the one added in 2017) were large, full-service garden centers that sold a wide variety of both native and non-native plants. Marketing materials included a $22 \times 28$-inch poster and plant tags $(2 \times 4.6$ inches and $3 \times 5.6$ inches $)$ that listed four benefits of native grasses (Fig. 1). The signs were designed by a local professional designer and produced by Fast Signs (St. Louis Park, MN). Custom plant tags were designed and produced by Master Tag (Montague, MI). Store employees were instructed to staple or insert the custom plant tags to all native grass and sedge containers at each garden center.

At four of the five garden centers, the POS posters were surrounded by containers of native grasses, creating a display within the herbaceous perennials store sales area (Fig. 2). The fifth garden center placed the poster within the traditional lines of gallon pots of the grass section, also within the herbaceous perennials sales area. Posters and plant tags were in place from the beginning of the gardening season in April to the end of the season in the fall. The sign and plant tags also were posted online for any garden center to use (Narem and Meyer, 2017b).

Consumer survey. We developed a one-page consumer survey

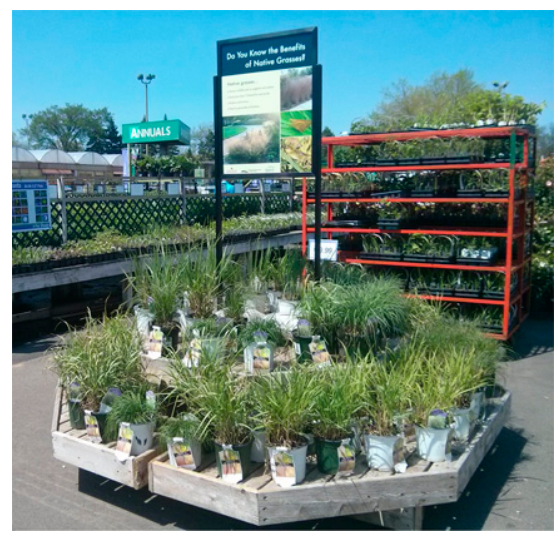

Fig. 2. Native grass point of sale display at participating garden center in Minnesota marketing study in 2016-17.

related to the POS display that consisted of four parts: 1) consumer reaction to the display and purchasing choice; 2) consumer knowledge of native grass benefits, measured subjectively and objectively; 3 ) willingness to purchase; and 4) demographic characteristics (Table 1). We surveyed consumers in the stores between 1 May and 31 Aug. in 2016 and 2017. Each location was visited a minimum of two times per year, for at least $3 \mathrm{~h}$ per visit during busy weekend or sales promotions. We attempted to solicit participants after they had an opportunity to see the marketing materials related to native grasses. We intercepted consumers at 
Table 1. Consumer survey questions and how they were used to measure purchasing decisions at five Minnesota garden centers using native grass marketing materials in 2016-17.

Question Variable

Answer and coding description

Q.1. Do you recall seeing the native grasses display with this sign?

Q.2. After seeing the native grass display, did you (check all that apply):

Q.3.1. Have you ever purchased a native grass before today?

Q.3.2. Did you purchase a native grass today?

Q.4. How would you rate your knowledge level on the benefits of native grasses?

Q.5a. Native grasses need a lot of pesticides and fertilizer.

Q.5b. Native grasses attract wildlife such as songbirds and turkeys.

Q.5c. Native grasses help reduce soil erosion.

Q.5d. Native grasses can feed more than 75 butterflies and moths.

Q.6a. If I know native grasses are beneficial for wildlife such as songbirds and turkeys, I would be more willing to purchase a native grass.

Q.6b. If I know native grasses are beneficial for butterflies and moths, I would be more willing to purchase a native grass.

Q.6c. If I know native grasses help to reduce soil erosion, I would be more willing to purchase a native grass.

Q.6d. If I know native grasses need no pesticides or fertilizer, I would be more willing to purchase a native grass.

Q.6e. I would not be willing to purchase native grasses because they do not have colorful flowers.

Q.7a. Yard size (respondents checked appropriate option)

Q.7b. Age (respondents checked appropriate option)

Q.7c. Gender (respondents checked appropriate option)
Observation of display

Reaction to the display

Previous purchase

Purchase decision

Subjective knowledge level

Objective knowledge level

Consumer willingness to purchase native grasses based on their

environmental benefits

Consumer willingness to

purchase based on aesthetics

Yard size

Age (years)

Gender $\mathrm{l}=$ saw the display, $0=$ did not see the display

a) 1. purchased a native grass (planned), 2. purchased a native grass (unplanned); b) noticed native grass, c) examined native grass, d) considered purchasing native grass, e) wanted to purchase, but already had similar grasses, and f) wanted to purchase but did not have room to plant; $1=$ yes, $0=$ no

$\mathrm{l}=$ previously purchased a native grass, $0=$ never previously purchased a native grass

$1=$ purchased a native grass that day, $0=$ did not purchase a native grass that day

$1=$ very unknowledgeable, $2=$ somewhat unknowledgeable, $3=$ neutral, $4=$ somewhat knowledgeable, 5 = very knowledgeable

$\mathrm{l}=$ true, 2 = false, 0 = I don't know

$1=$ true, 2 = false, 0 = I don't know

$1=$ true, 2 = false, $0=\mathrm{I}$ don't know

$\mathrm{l}=$ true, 2 = false, $0=\mathrm{I}$ don't know

An index variable created from the above four true/ false questions, each correct question was worth 1 point, maximum value $=4$, minimum value $=0$

1 = strongly disagree, 2 = somewhat disagree, $3=$ slightly disagree, $4=$ neutral, $5=$ slightly agree, $6=$ somewhat agree, $7=$ strongly agree

$1=$ strongly disagree, $2=$ somewhat disagree, $3=$ slightly disagree, $4=$ neutral, $5=$ slightly agree, $6=$ somewhat agree, $7=$ strongly agree

1 = strongly disagree, 2 = somewhat disagree, $3=$ slightly disagree, $4=$ neutral, $5=$ slightly agree, $6=$ somewhat agree, $7=$ strongly agree

1 = strongly disagree, 2 = somewhat disagree, 3 = slightly disagree, $4=$ neutral, $5=$ slightly agree, $6=$ somewhat agree, $7=$ strongly agree

A factor variable synthesized from the above four willingness-to-purchase statements

1 = strongly disagree, 2 = somewhat disagree, $3=$ slightly disagree, $4=$ neutral, $5=$ slightly agree, $6=$ somewhat agree, $7=$ strongly agree

$0=$ no yard, $1=$ yard $<1$ acre, $2=$ yard $>1$ acre $(1$ acre $=$ 0.4047 ha)

1 = younger than $20,2=20-30,3=31-40,4=41-$ $50,5=51-60,6=$ older than 60

1 = male, 2 = female the store exit or as they left the native grass section of the stores. All consumers were asked if they would be willing to complete a brief survey of questions concerning native grasses. Participants were given a clipboard with the survey and completed it without additional assistance. At some stores, surveys were handed to consumers and completed at checkout.
The first question in the survey asked if the respondent remembered seeing the native grass poster. If the respondent answered yes, they could choose multiple ways in which they 
reacted to the display using a multiresponse question. If the respondent answered no, they skipped to question 3.1, which asked if they had purchased a native grass before today. Question 3.2 asked if they had purchased a native grass that day to catch those that had bought a native grass without seeing the display (Table 1).

Consumer knowledge was assessed both subjectively and objectively. Subjective knowledge was assessed by asking consumers to rate their knowledge on native grasses using a five-point scale ( $1=$ very unknowledgeable to $5=$ very knowledgeable). Objective knowledge of native grasses benefits was tested using four true or false questions, each referring to a specific benefit (Table 1 ). The answers to each question could be found on the poster located in the display; however, when the participants were answering the survey, they were not standing directly beside the poster, so they could not read the information. The correct vs. incorrect response rate of each question was calculated ("no" and "I don't know" responses were combined into one category) and compared using Pearson's $\chi^{2}$ test. A variable was created by adding up the four true or false questions (1 point for every right answer). To test the hypothesis that the display increased consumers' knowledge of native grasses, both subjective and objective knowledge variables were compared between respondents who did and did not see the POS display using Pearson's $\chi^{2}$ test.

Willingness to purchase native grasses was assessed using five statements with Likert scales to measure agreement $(\mathrm{l}=$ strongly disagree to 7 = strongly agree). Four statements declared an increased willingness to purchase a native grass if the consumer knew about a native grass benefit. Each statement listed a different benefit. The responses to the four statements were synthesized into one variable using principal component factor analysis. One statement declared an unwillingness to purchase a native grass due to their lack of colorful flowers and assessed consumer willingness to purchase based upon aesthetics (Table 1).

A binary probit regression model (R Core Team, 2017) was used to determine which factors influenced a consumer's decision to buy a native grass. The dependent variable was the answer to question 3.2 (Table 1), which asked if the respondents had bought a native grass that day irrespective of whether they saw the poster or not. The independent variables were all other variables from the survey except the consumer reaction to the display (Table 1). Interactions between variables were included as independent variables in the model but were not significant, and so they were excluded from the final model. Correlations between variables were analyzed.

Sales Data. We requested native grass sales data from garden centers for the year previous to the study (2015), and each year of the study (2016 and 2017). We hypothesized that increased sales could be used as an objective measure of consumer choice and preference for native grasses and to measure success of the POS displays.

\section{Results}

A total of 341 surveys were collected over 2 years $(\mathrm{n}=196$ in 2016 and $n=145$ in 2017). Of the 341 surveys, 336 were usable for analysis. Of the 336 surveys, 174 were from native plant specialty garden centers and 162 were from traditional garden centers that sold both native and nonnative plants. Response number varied by store, from 23 to 64 surveys per store per year. Larger stores, with more customers, as expected had more surveys; however, the total number of surveys and the similar distribution between native plants only and traditional garden centers enabled us to believe this sample was representative of the shoppers at these stores. Approximately 50 (15\%) of the surveys were completed at checkout when the customer agreed to complete the survey when asked by a store employee; the remaining surveys were distributed by a research associate. We found no response differences between the two methods of survey distribution.

The majority of respondents reported they had yards less than 1 acre in size, were female, and older than 41 years (Table 2 ). There were no significant differences in age and gender between garden centers. The average yard size was significantly larger $(P<0.005)$ at native plant garden centers compared with traditional garden centers. There were no
Table 2. Demographic results for survey respondents $(n=336)$ from five Minnesota garden centers using native grass marketing methods in 2016-17.

\begin{tabular}{lc}
\hline Demographics & $\begin{array}{c}\text { Proportion of } \\
\text { respondents }(\%)\end{array}$ \\
\hline Yard size & \\
No yard & 4.72 \\
Yard $<1$ acre & 66.98 \\
Yard >1 acre & 28.30 \\
Age (years) & \\
Younger than 20 & 0.30 \\
$20-30$ & 8.51 \\
31-40 & 16.11 \\
$41-50$ & 21.28 \\
$51-60$ & 21.28 \\
Older than 60 & 32.52 \\
Gender & \\
Male & 29.54 \\
Female & 70.46 \\
\hline${ }^{\mathrm{z}}$ acre $=0.4047$ ha. &
\end{tabular}

significant differences in demographics between years.

A total of $152(45.7 \%)$ respondents indicated they saw the native grass POS display (Fig. 3). Of those who saw the display, 22 made a planned purchase, 4 made an unplanned purchase of a native grass, and 4 made a purchase but did not indicate if it was planned or unplanned (Fig. 4). Participants were allowed multiple responses to question 2 (Table 1). Almost one-half (46.7\%) of respondents noticed the grasses; $34.9 \%$ examined the grasses; $28.3 \%$ considered purchasing a grass; $15.8 \%$ wanted to purchase a grass but already had similar grasses, and $9.2 \%$ wanted to purchase but did not have room (Fig. 3 ).

Of all the respondents, both those who saw the poster and those who did not, 192 (58.2\%) had previously purchased a native grass. The survey asked respondents again if they had bought a native grass. The purpose of that question was to count the respondents who did not see the poster and bought a native grass that day. Eighty-four respondents (30.7\%) indicated that they had bought a native grass that day, and of those 84,54 had seen the display. This number conflicts with the number of people who indicated in question 1 that they purchased a native grass after seeing the display, revealing participants' different answers to the same question. 


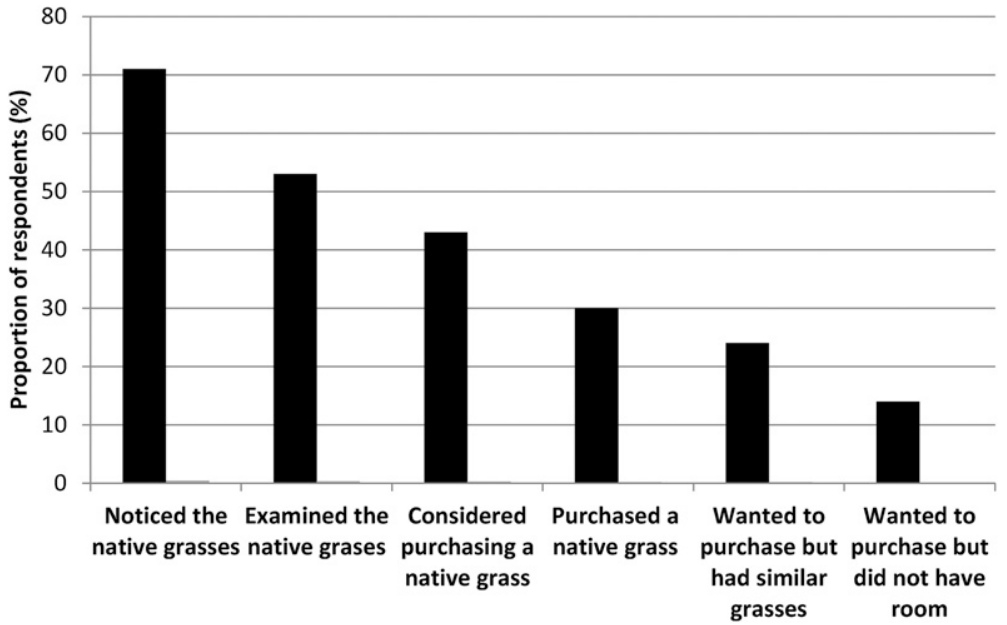

Fig. 3. Multiresponses from respondents $(n=152)$ who indicated they saw the point of sale display poster in a native grass marketing study at five Minnesota garden centers in 2016-17.

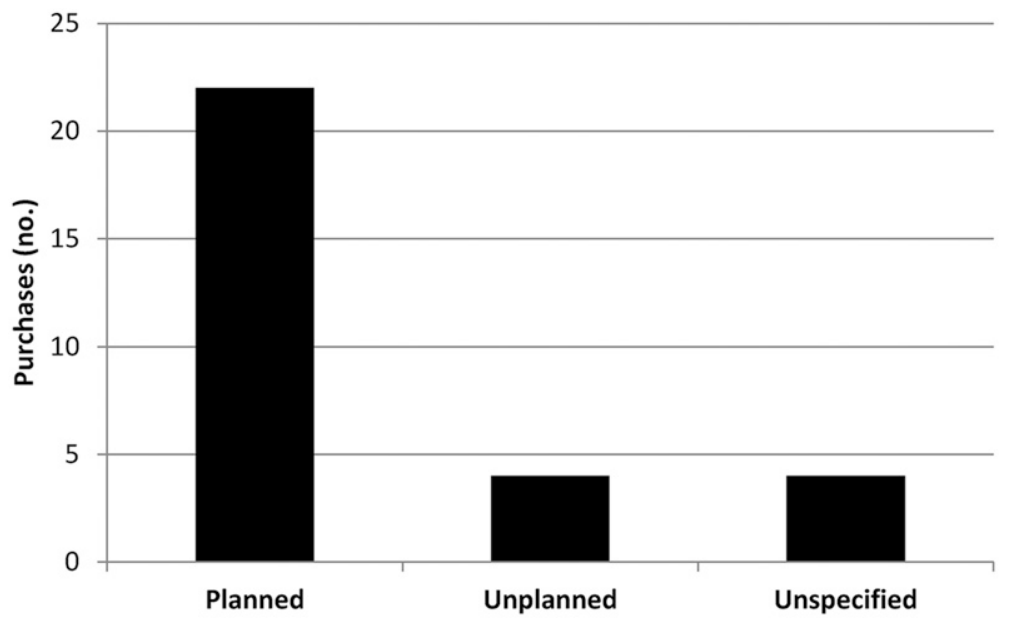

Fig. 4. Respondents who "purchased a native grass" (Fig. 3 ) are further defined as to the type of purchase from a marketing study at five Minnesota garden centers in 2016-17.

On average, respondents rated their knowledge of native grasses as 2.85 , between somewhat unknowledgeable (2) and neutral (3). There was a significant difference $(P<$ 0.001 ) in subjective knowledge between those who saw the POS display $($ mean $=3.161)$ and those who did not $($ mean $=2.596)$. All respondents' average level of objective knowledge was 3.321 (between three and four right answers out of four questions). The difference in objective knowledge between those who saw the POS display $($ mean $=3.434)$ and those who did not see the poster (mean $=3.224)$ was not significant. It is possible that consumers who saw the native grass displays were intrigued, so they noticed the sign but did not pay attention what was on the sign. Then they answered that they saw the POS but did not get anything from it.

The benefit known by the most respondents was that native grasses help reduce soil erosion, with 92\% answering the true or false question correctly. This was followed by native grasses do not need a lot of pesticides and fertilizers, with $89 \%$ correct responses and attract wildlife such as songbirds (Passeri) and turkeys (Meleagris gallopavo) with $86 \%$ correct responses. Only $69 \%$ of respondents knew native grasses feed more than 75 butterflies and moths (Fig. 5). When the percentage of correct responses was compared among questions, a $\chi^{2}$ test showed there was a significant difference between questions $\left[\chi^{2}=82.8, \mathrm{df}=3\right.$, $P<0.001$ (Fig. 5)].

On average, respondents agreed that they would be more willing to purchase a native grass if they knew of its benefits. Respondents most agreed with the statement that they would be more willing to purchase native grasses if they knew that native grasses needed no pesticides or fertilizers $($ mean $=$ 6.284). Knowing that grasses are beneficial for butterflies and moths (mean = 6.213 ), help reduce soil erosion $($ mean $=$ $6.165)$, and are beneficial for songbirds and turkeys $($ mean $=5.940)$ also made consumers more willing to purchase a native grass. Consumers strongly to somewhat disagreed $($ mean $=1.985)$ with the statement that they would be less willing to purchase a native grass if it did not have colorful flowers.

The binary probit model estimates showed that seeing the POS display increased the likelihood of a consumer buying a native grass (Table 3 ). If a consumer had previously purchased a native grass, they were more likely to purchase a native grass in the future. Neither knowledge level nor any of the demographics significantly increased likelihood of purchase. A willingness to purchase native grasses based on knowledge of their benefits was correlated with an increased likelihood of purchasing a native grass, whereas a willingness to purchase native grasses even though they do not have colorful flowers was not shown to be significantly correlated. We found willingness to purchase question 6a (based on wildlife benefits) was significantly correlated with questions $6 \mathrm{~b}, 6 \mathrm{c}$, and 6d (feeds butterflies, minimizes soil erosion, and reduced input questions); however, question 6e (aesthetics of grass flowers) was not correlated with questions $6 a, 6 b, 6 c$, and $6 \mathrm{~d}$. There was also a significant positive correlation between question 4 (personal assessment of grass benefits or subjective knowledge), and the true and false objective knowledge benefits statements poised in questions $5 \mathrm{a}, 5 \mathrm{~b}, 5 \mathrm{c}$, and $5 \mathrm{~d}$.

Obtaining consistent sales data from the garden centers in this study was difficult. One garden center refused to share any sales data, regardless of their original agreement when the project started. Two garden centers were unable to provide any 
comparative sales data for 2015 , showing premarketing sales. Two of the garden centers included wholesale data with their retail sales data. Therefore, we were unable to objectively measure the effect of the POS display on overall grass sales. Overall, for each garden center however, the sale of native grasses increased each year of this project (Table 4). Ideally, we should have invested much more time in working with stores to obtain accurate sales data.

\section{Discussion and conclusions}

In this study, we sought to better understand whether an informational POS display increased consumer knowledge of native grasses and whether it influenced consumer-purchasing decisions. Our results showed that the seeing the POS display did not influence the objective knowledge of consumers but did increase the likelihood of a native grass purchase. An explanation for this could be that the POS display influenced consumers by drawing attention to the product without their actually reading and learning from the information on the display.

Subjective knowledge level of those that saw the display was significantly greater than those who had not. There could be many reasons for these results. After seeing the POS display, consumers may feel they have greater knowledge on a topic without actually internalizing information from the display. Because the POS displays were located in or near the native grass section at each garden center, consumers interested in native grasses were more likely to see the displays. Alternatively, consumers interested in native grasses may judge themselves to be more knowledgeable about the topic than they actually are.

Willingness to purchase native grasses based on their benefits was positively correlated to purchasing a native grass (Table 3 ). This leads to the conclusion that the consumers who are buying native grasses appreciate the benefits that they provide. However, consumer knowledge (measured by subjective knowledge survey question 4 and objective knowledge survey questions $5 \mathrm{a}-\mathrm{d}$ ) did not (according to the probit model Table 3) influence consumer decisions to purchase a grass. Thus, we cannot confirm that knowing

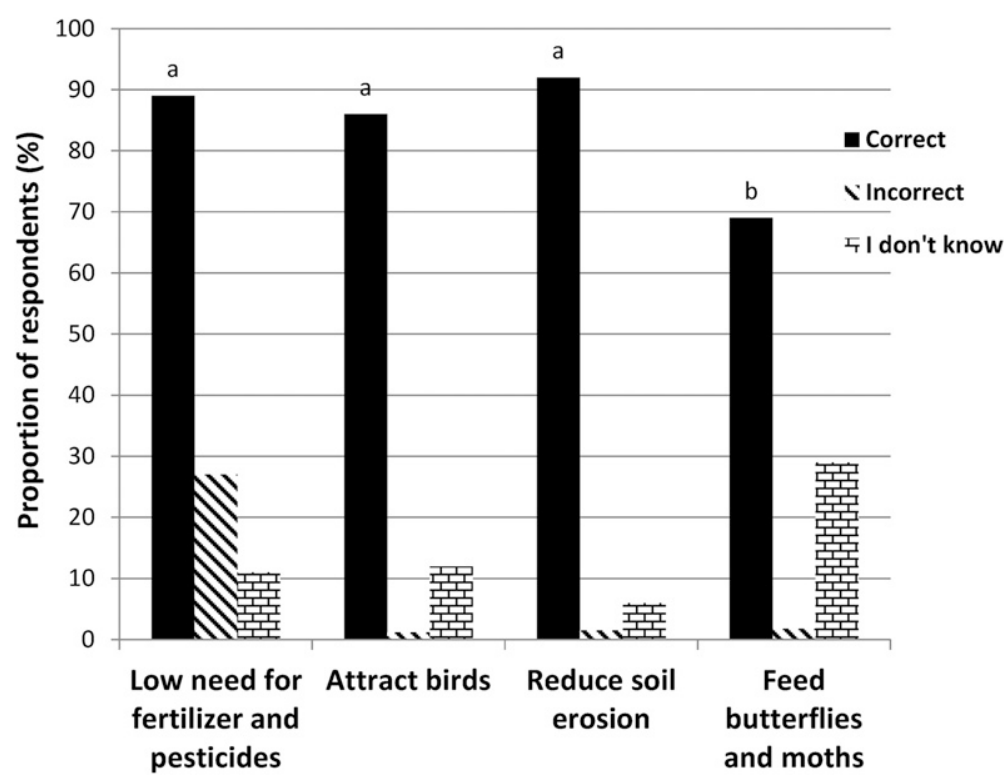

Fig. 5. Responses to questions that measured respondents' objective knowledge of four native grass benefits in a marketing study at five Minnesota garden centers in 2016-17. Correct responses to the "feed butterflies and moths" was significantly lower than the other benefits, as indicated by different letters, $P<0.001$.

Table 3. Significance of survey variables in relation to consumer native grass purchasing decisions in a marketing study at five garden centers in Minnesota in 2016-17.

\begin{tabular}{lc}
\hline Variable & Coefficient (SE) \\
\hline Observation of the display & $0.57(0.19)^{* *}$ \\
Previous purchase & $0.43(0.21)^{*}$ \\
Subjective knowledge level & $-0.06(0.08)$ \\
Objective knowledge level & $-0.09(0.09)$ \\
Consumer willingness to purchase based on benefits & $0.40(0.14)^{* *}$ \\
Consumer willingness to purchase based on aesthetics & $-0.07(0.06)$ \\
Yard size & $0.16(0.17)$ \\
Age & $-0.01(0.07)$ \\
Gender & $-0.06(0.20)$ \\
Number of observations & 245 \\
Log likelihood & -129.78 \\
Likelihood ratio $\chi^{2}(9)$ & 40.61 \\
$P>\chi^{2}$ & 0.0000 \\
\hline
\end{tabular}

${ }^{*},{ }^{* *}$ Significant at $P \leq 0.05$ or 0.01 , respectively.

Table 4. Changes in native grass sales from four Minnesota garden centers conducting a native grass marketing project in 2015-17.

\begin{tabular}{llccccc}
\hline & & \multicolumn{2}{c}{ Change units (\%) } & & \multicolumn{2}{c}{ Change dollars (\%) } \\
Garden center & \multicolumn{1}{c}{ Data type } & 2015-16 & $\mathbf{2 0 1 6 - 1 7}$ & & $\mathbf{2 0 1 5}-\mathbf{1 6}$ & $\mathbf{2 0 1 6 - 1 7}$ \\
\hline A & Retail + wholesale & na & na & & 35 & 23 \\
B & Retail only & na & 57 & & na & 31 \\
C & Retail only & 28 & 26 & & na & na \\
D & Retail + wholesale & na & na & & na & 4 \\
\hline
\end{tabular}

na = no data available.

more about the benefits of native grasses would result in more purchases, however likely this correlation may seem. We found that consumers who had previously purchased a native grass were more likely to purchase a native grass that day, indicating that native grass purchasers may be repeat consumers.

Limitations to the study included placing the POS display in the native grass section at the two 
largest garden centers. This made it less likely that people who had no intention of buying a native grass would see that POS poster because they would be less likely to be in that area of the store. This could cause bias in questions because people that were more likely to buy a native grass (be in the native grass area) were more likely to see the poster. Also, the survey methodology relied on self-reported data, which may lead to bias.

Many factors influence a consumer's buying choice, such as price, quality, and values (Ståhlberg and Maila, 2012). For this reason, although our data showed a correlation between the POS display and consumer buying decision, it is difficult to definitively know what role the display played and the total extent to which it influenced a purchasing decision. An informational campaign ran concurrently with the marketing study, which promoted the benefits of native grasses and their relationship with butterflies and moths. This campaign included presentations to University of Minnesota Extension Master Gardeners at state and regional gatherings, an informational website (Narem and Meyer, 2017b), and the dissemination of news articles and press releases. Additional research could be conducted to learn how these educational campaigns shape consumer opinions and desires and how they influence consumer decisions at POS displays. Future research could include the use of multiple POS signs, in-depth surveys, or in store interviews to better understand consumer knowledge and how it affects purchasing decisions within the horticultural industry.

\section{Literature cited}

Areni, C.S., D.F. Duhan, and P. Kiecker. 1999. Point-of-purchase displays, product organization, and brand purchase likelihoods. J. Acad. Mktg. Sci. 27:428441 .

Barton, S.S. and B.K. Behe. 2017. Retail promotion and advertising in the green industry: An overview and exploration of the use of digital advertising. Hort Technology 27:99-107.

Breeze, T.D., A.P. Bailey, S.G. Potts, and K.G. Balcombe. 2015. A stated preference valuation of the non-market benefits of pollination services in the UK. Ecol. Econ. 111:76-85.

Brzuszek, R.F. and R.L. Harkess. 2009. Green industry survey of native plant marketing in the southeastern United States. HortTechnology 19:168-172.

Brzuszek, R.F., R.L. Harkess, and L. Kelly. 2010. Survey of master gardener use of native plants in the southeastern United States. HortTechnology 20:462466.

Diffendorfer, J.E., J.B. Loomis, L. Ries, K. Oberhauser, L. Lopez-Hoffman, D. Semmens, B. Semmens, B. Butterfield, K. Bagstad, J. Goldstein, R. Wiederholt, B. Mattsson, and W.E. Thogmartin. 2014. National valuation of monarch butterflies indicates an untapped potential for incentive-based conservation. Conserv. Lett. 7:253-262.

Hahn, M. and C.A. Brühl. 2016. The secret pollinators: An overview of moth pollination with a focus on Europe and North America. Arthropod-Plant Interact. 10:21-28.

Hall, C.R. and M.W. Dickson. 2011. Economic, environmental, and health/ well-being benefits associated with green industry products and services: A review. J. Environ. Hort. 29:96-103.

Hamill, N. 2005. Natives near and far. Ornamental Outlook 14(6):31-32.

Helfand, G.E., J.S. Park, J.I. Nassauer, and S. Kosek. 2006. The economics of native plants in residential landscape designs. Landsc. Urban Plan. 78:229-240.

Huddleston, P., B.K. Behe, S. Minahan, and R.T. Fernandez. 2015. Seeking attention: An eye tracking study of in-store merchandise displays. Intl. J. Retail Distrib. 43:561-574.

Jennersten, O. 1984. Flower visitation and pollination efficiency of some north European butterflies. Oecologia 63:80-89.

Khachatryan, H., B. Campbell, C. Hall, B. Behe, C. Yue, and J. Dennis. 2014. The effects of individual environmental concerns on willingness to pay for sustainable plant attributes. HortScience 49:69-75.

Khachatryan, H., A.L. Rihn, B. Campbell, C. Yue, C. Hall, and B.K. Behe. 2017. Visual attention to eco-labels predicts consumer preferences for pollinator friendly plants. Sustainability 9:1743-1756.

Kiesling, F.M. and C.M. Manning. 2010. How green is your thumb? Environmental gardening identity and ecological gardening practices. J. Environ. Psychol. 30:315-327.

McKinnon, G.F., J.P. Kelly, and E.D. Robison. 1981. Sales effects of point-ofpurchase in-store signing. J. Retailing 57: 49-63.

Meyer, M.H. 2013. Ornamental grasses for cold climates. $3 \mathrm{rd}$ ed. Univ. Minnesota Ext. Publ. 06411, Chaska, MN.

Narem, D.M. and M.H. Meyer. 2017a. Native prairie graminoid host plants of Minnesota and associated Lepidoptera: A literature review. J. Lepidopterists' Soc. 71:225-235.

Narem, D.M. and M.H. Meyer. 2017b. Native grasses. 5 Aug. 2017. <http:// grasses.cfans.umn.edu>.

O'Brien, B.C. 1996. Xeriscaping: Sources of new native ornamental plants, p. 536539. In: J. Janick (ed.). Progress in new crops. ASHS Press, Alexandria, VA.

R Core Team. 2017. R: A language and environment for statistical computing. 12 Apr. 2018. <https://www.R-project.org/>.

Rihn, A. and H. Khachatryan. 2016. Does consumer awareness of neonicotinoid insecticides influence their preferences for plants? HortScience 51:388-393.

Ståhlberg, M. and V. Maila. 2012. Shopper marketing: How to increase purchase decisions at the point of sale. Kogan Page, London, UK.

Tallamy, D.G. and K.J. Shropshire. 2009. Ranking Lepidoptera use of native versus introduced plants. Conserv. Biol. 23:941947.

U.S. Fish and Wildlife Service. 2001. National wildlife refuge system: Biological integrity, diversity, and environmental health. Release no. 366. U.S. Fish Wildlife Serv. Transmittal Sheet. Part 601 FW 3. U.S. Fish Wildlife Serv., Washington, DC.

Yue, C., J.H. Dennis, B.K. Behe, C.R. Hall, B.L. Campbell, and R.G. Lopez. 2011. Investigating consumer preference for organic, local, or sustainable plants. HortScience 46:610-615.

Yue, C., B. Campbell, C. Hall, B. Behe, J. Dennis, and H. Khachatryan. 2015. Consumer preference for sustainable attributes in plants: Evidence from experimental auctions. Agribusiness Intl. J. 32:222-235.

Wollaeger, H.M., K.L. Getter, and B.K. Behe. 2015. Consumer preferences for traditional, neonicotinoid-free, bee-friendly, or biological control pest management practices on floriculture crops. HortScience 50:721-732. 